\title{
Brazil nut: nutritional benefits from a unique combination of antioxidants
}

\author{
Alan Giovanini de Oliveira Sartori ${ }^{\mathrm{a}^{*}}$, Marisa A.B. Regitano-d'Arce ${ }^{\mathrm{a}}$ and Leif H. Skibsted ${ }^{\mathrm{b}}$ \\ aDepartment of Agri-food Industry, Food and Nutrition, Luiz de Queiroz College of Agriculture, University of São Paulo, Piracicaba, SP, \\ Brazil \\ bepartment of Food Science, Faculty of Science, University of Copenhagen, Frederiksberg, Denmark \\ *Corresponding author: Alan Giovanini de Oliveira Sartori, Department of Agri-food Industry, Food and Nutrition, Luiz de Queiroz Col- \\ lege of Agriculture, University of São Paulo, Piracicaba, SP, Brazil. E-mail: alangosartori@usp.br \\ DOI: $10.31665 / J F B .2020 .9216$ \\ Received: March 27, 2020; Revised received \& accepted: March 31, 2020 \\ Citation: de Oliveira Sartori, A.G, Regitano-d'Arce, M.A.B., and Skibsted, L.H. (2020). Brazil nut: nutritional benefits from a unique com- \\ bination of antioxidants. J. Food Bioact. 9: 36-39.
}

\begin{abstract}
Brazil nut is the seed of the Bertholletia excelsa tree, which grows naturally in the rainforests of South America. The production chain is environmentally sustainable as seeds are collected from the hard-shelled indehiscent fruits as they fall on the forest floor, without the need of deforestation. Brazil nut is among the most popular and commercially important tree nuts, and a reduced risk of coronary heart disease among other health benefits have been related to its consumption. A high content of both soluble and bound phenolic antioxidants, especially in the brown skin of the kernel, partly explains this positive health effect together with a high content of oleic acid and linoleic acid. The $\omega-3 / \omega-6$ is less favorable, but the relatively high content of delta-tocopherol for a tree nut and the highest selenium (Se) level among all foods warrant other health benefits such as antioxidant activity and anticancer effects. Se levels in Brazil nuts vary considerably depending on origin, and recommendations for their safe consumption should be made and added in food labels in order to avoid selenosis.
\end{abstract}

Keywords: Bertholletia excelsa; Brazil nut; Phenolic compounds; Selenium; Tocopherols; Antioxidant.

Brazil nut is among the most popular and commercially important tree nuts, along with pecans, walnuts, pine nuts, pistachios, macadamia nuts, hazelnuts, almonds and cashews (Venkatachalam and Sathe, 2006). Brazil nut, with the Portuguese name Castanha do Pará, named after the Brazilian state of Pará, is available raw in-shell or shelled and dried. Dried Brazil nuts are increasingly being added to foods such as baked goods and breakfast cereals. Botanically, nuts are fruits with one seed, but Brazil nut as used in food, is rather a single seed of a fruit with up to 24 seeds inside an indehiscent shell. The Food and Drug Administration (FDA) of the United States now allows a health claim for tree nuts, including Brazil nuts (FDA, 2003). The recommendation of a daily intake of approximately $40 \mathrm{~g}$ of tree nuts as part of a diet low in saturated fats and cholesterol in order to reduce the risk of coronary heart diseases is based on epidemiological studies (FDA, 2003). There is also evidence of anti-cancer and more general antioxidant ef- fects related to a regular Brazil nut consumption (Cardoso et al., 2017). Lipid-rich Brazil nuts have a unique composition of plant phenols and tocopherol homologues that are atypically combined with seleno-amino acids, for which synergistic antioxidant effects are unexplored or at least not understood. Table 1 summarizes the major findings reported in this article concerning the chemical composition, especially antioxidants, of Brazil nut and the health effects related to its regular consumption.

As the other tree nuts, Brazil nut has a low water activity with lipid and protein content of $60-70 \%$ and $15 \%$, respectively (Unicamp, 2006; Venkatachalam and Sathe, 2006; USDA, 2019). The lipid content is high and almost comparable to macadamia nut with a lipid profile favorable to human health due to the high proportion of unsaturated fatty acids, mainly the essential linoleic acid and oleic acid. An effect of lowering total and low-density lipoproteincholesterol (LDL-c) while maintaining or increasing high-density 
Table 1. : The chemical composition, especially antioxidants, of Brazil nuts and the health effects related to its regular consumption

\begin{tabular}{|c|c|c|}
\hline Subject & Key findings & References \\
\hline \multirow[t]{2}{*}{$\begin{array}{l}\text { Hydrosoluble } \\
\text { phenolic } \\
\text { compounds }\end{array}$} & $\begin{array}{l}\text { Predominately found in the brown skin that covers the kernel, detected so far are } \\
\text { phenolic acids and flavonoid derivatives like gallic acid, gallocatechin, protocatechuic } \\
\text { acid, catechin, vanillic acid, taxifolin, myricetin, ellagic acid, sinapic acid and quercetin }\end{array}$ & $\begin{array}{l}\text { John and Shahidi } \\
\text { (2010); Gomes and } \\
\text { Torres (2016) }\end{array}$ \\
\hline & $\begin{array}{l}\text { Relevant amounts of ellagic acid derivatives found in aqueous } \\
\text { extracts of bark biomass residues of the Brazil nut tree }\end{array}$ & Silva et al. (2019) \\
\hline Tocopherols & Brazil nut has remarkable levels of delta-tocopherol, in comparison with other tree nuts & $\begin{array}{l}\text { Miraliakbari and } \\
\text { Shahidi (2008b) }\end{array}$ \\
\hline Selenium & $\begin{array}{l}\text { Selenium levels vary significantly depending on the nut origin. } \\
\text { Therefore, recommendations of adding Se levels information based } \\
\text { on the origin of the seeds in retail labelling should be made }\end{array}$ & Silva Jr. et al. (2017) \\
\hline \multirow{2}{*}{$\begin{array}{l}\text { Effects of } \\
\text { processing on } \\
\text { nutrient levels }\end{array}$} & Selenium levels decreased up to $73 \%$ during water-extraction process & Sartori et al. (2020) \\
\hline & $\begin{array}{l}\text { Alpha-tocopherol losses are higher than gamma-tocopherol } \\
\text { losses in Brazil nut oil during storage }\end{array}$ & Sartori et al. (2018a) \\
\hline \multirow[t]{3}{*}{ Health effects } & No selenosis reported in health populations with diets rich in selenium from Brazil nuts & $\begin{array}{l}\text { Martens et al. (2015); } \\
\text { Lemire et al. (2012) }\end{array}$ \\
\hline & $\begin{array}{l}\text { Consumption of Brazil nuts with high Se levels may have } \\
\text { a pro-inflammatory effect in obese women }\end{array}$ & Duarte et al. (2019) \\
\hline & $\begin{array}{l}\text { Anti-cancer and antioxidant effects related to a regular } \\
\text { Brazil nut consumption was reported }\end{array}$ & Cardoso et al. (2017) \\
\hline
\end{tabular}

lipoprotein-cholesterol (HDL-c), as seen for the intake of olive oil, is assigned to oleic acid.

Se levels vary from one seed to another $(<0.5$ to $146.6 \mu \mathrm{g} \mathrm{Se} / \mathrm{g})$ and a single Brazil nut (ca. $3 \mathrm{~g}$ ) may overcome the daily dietary recommended intake for this mineral of $70 \mu \mathrm{g}$ (Silva Jr. et al., 2017). Se levels also vary according to the seed origin, mostly due to Se soil levels and soil acidity, and average values of $66.1 \mu \mathrm{g}$ $\mathrm{Se} / \mathrm{g}$ (Amazonas), $51.2 \mu \mathrm{g} \mathrm{Se} / \mathrm{g}$ (Pará), $10.2 \mu \mathrm{g} \mathrm{Se} / \mathrm{g}$ (Roraima), 3.0 $\mu \mathrm{g} \mathrm{Se} / \mathrm{g}$ (Acre), and $2.4 \mu \mathrm{g} \mathrm{Se} / \mathrm{g}$ (Mato Grosso) were reported according to the Brazilian state where the seeds were collected (Silva Jr. et al., 2017). Individuals from some Amazonian populations with selenium-rich diets, especially due to Brazil nut consumption, and consequently, Se blood levels above the safe levels, did not show toxicity symptoms (Martens et al., 2015; Lemire et al., 2012). However, preliminary studies revealed that consumption of Brazil nuts with high Se levels may have a pro-inflammatory effect in obese women (Duarte et al., 2019). Thus, the consumption of Brazil nuts should be moderate. Furthermore, consumption recommendations from the Government should be considered in order to prevent selenosis. Since analysis of Se levels in individual nuts is expensive and labor-demanding, an affordable alternative could be the description of the expected Se level in the labels of Brazil nuts and products containing Brazil nuts per portion, based on the seeds origin. This labeling initiative could also raise worldwide consumer awareness on the unique health benefits related to Brazil nuts.

In Brazil nuts, approximately $85 \%$ of Se is covalently bound to proteins, mainly replacing sulfur in selenomethionine and selenocysteine (Kannamkumarath et al., 2002; Chunhieng et al., 2004). The biological activity of Se in mammals is normally assigned to its antioxidant activity when incorporated in glutathione peroxidases (GPx), iodothyronine deiodinases (IDI), thioredoxin reductases (TR) and selenoprotein P (SePP), which are among the 25 selenoenzymes identified so far (Cardoso et al., 2017). The effect of processing, such as heating or pasteurization, on Se levels in Brazil nuts is still not clear, despite the increasing use of this tree nut in food formulations. Sartori et al. (2020) estimated Se losses during water-extraction to produce water-soluble Brazil nut extract (Brazil nut milk) and Brazil nut flour to be $73 \%$. Further studies are needed in order to identify the effect of every process step, although Se may be predominantly lost during the flour-drying step, since organoseleno compounds formed by selenomethionine in the presence of glucose under heating may volatilize (Tsai et al., 1998).

Along with Se, Brazil nut contains other compounds with antioxidant activity, such as zinc and phenolics, mainly tocopherols, which play a role in human health. Antioxidants are substances that when present at low concentrations compared with those of an oxidizable substrate significantly delay or prevent oxidation (Halliwell, 1990). In Brazil nuts, there are oxidizable unsaturated fatty acids as substrates, and antioxidants are important in nature for preserving the vitality of the seed. During processing and storage of Brazil nuts as a food, antioxidants become important for protection of the lipids to keep them nutritionally and sensorially acceptable, as lipid oxidation implies loss of nutritional value and generation of off-flavors (Miraliakbari and Shahidi, 2008a; Zajdenwerg et al., 2011).

There are several studies concerning the oxidative stability of Brazil nuts, Brazil nut oil, and Brazil nut flour during storage, mainly monitoring hydroperoxides, volatiles or the tendency of free radicals formation (Gutierrez, Regitano-d'Arce, and Rauen-Miguel, 1997; Regitano-d'Arce, 1998; Vieira and Regitanod'Arce, 1999; Miraliakbari and Shahidi, 2008a; Zajdenwerg et al., 2011; Sartori et al., 2018a, Sartori et al., 2018b, Sartori et al., 2018c). When compared with pine nut, walnut and hazelnut oils, Brazil nut oil along with pecan oil, showed to be the most stable oil during a storage test at $60{ }^{\circ} \mathrm{C}$ for 12 days, by monitoring the formation of headspace hexanal both for extraction with hexane and with a mixture of chloroform and methanol (Miraliakbari and Shahidi, 2008a). The resistance against autoxidation was hypothesized to be due to the lower degree of unsaturation of lipids and especially the absence of alpha-linolenic acid and to the presence of tocols and phospholipids in oils of pecans and Brazil nuts. The antioxidant mechanism of phospholipids in vegetable oils still re- 
mains unexplained with no studies evaluating antioxidant activity of phospholipids in Brazil nut oil. In contrast, tocopherols are known to donate hydrogen atoms to lipid peroxyl radicals halting propagation of autoxidation (Kamal-Eldin and Appelqvist, 1996). In Brazil nut oil, the alpha-tocopherol homologue seems to have the highest ability to act as antioxidant, as observed in a study with storage at a high temperature of $80{ }^{\circ} \mathrm{C}$ (Zajdenwerg et al., 2011). The chain-breaking mechanism operating was confirmed in another study, where the contents of alpha- and gamma-tocopherol present in cold-pressed Brazil nut oil were monitored under simulated retail conditions during five months (Sartori et al., 2018a).

Beta-tocopherol and gamma-tocotrienol are present only in trace amounts and vitamin $\mathrm{C}$ and carotenoids with antioxidant activity seems completely absent in Brazil nuts (USDA, 2019). In contrast, the content of delta-tocopherol is remarkable, as it amounts to almost $10 \%$ of the total concentration of the tocopherol homologues in marked contrast to other tree nut oils like hazelnuts, almonds and pecan oil (Miraliakbari and Shahidi, 2008b). Deltatocopherol is the least reducing of the tocopherol homologues, the least efficient as radical scavenger (Mortensen and Skibsted, 1997), and probably has little effect as antioxidant in the oil. However, delta-tocopherol, along with gamma-tocopherol, delta-tocotrienol and gamma-tocotrienol seems to have cancer-preventing effects stronger than alpha-tocopherol, by inhibiting the growth and inducing death of different types of cancer cells, and by being capable of suppressing cancer development in preclinical cancer models (Jiang, 2019; Li et al., 2011).

As with peanuts, phenolic compounds other than tocopherols are predominantly present in the brown skin that covers Brazil nut kernels (John and Shahidi, 2010). There are several studies concerning the in vitro antioxidant activity of Brazil nuts (Wu et al., 2004; Kornsteiner et al., 2006; Miraliakbari and Shahidi, 2008c; Abe et al., 2010; John and Shahidi, 2010; Gomes and Torres, 2016), which present inconsistent results, likely due to the variation in the presence (and if, in which proportion) or absence of the brown skin in the analyzed samples. Only two studies identified the bioactive compounds related to the antioxidant activity of Brazil nuts (John and Shahidi, 2010; Gomes and Torres, 2016). The brown skin was found to have more than $1.2 \mathrm{~g}$ of gallic acid equivalents (GAE) per $100 \mathrm{~g}$ of soluble phenolics and $0.35 \mathrm{~g} \mathrm{GAE} / 100 \mathrm{~g}$ of bound phenolics, while the whole nut had $0.52 \mathrm{~g} \mathrm{GAE} / 100 \mathrm{~g}$ of soluble phenolics and $18 \mathrm{mg} \mathrm{GAE} / 100 \mathrm{~g}$ of bound phenolics (John and Shahidi, 2010). Extracts prepared from the brown skin clearly had the highest in vitro antioxidant activities, and the major phenolics identified by HPLC-ESI(-)-MS were phenolic acids and flavonoid derivatives like gallic acid, gallocatechin, protocatechuic acid, catechin, vanillic acid, taxifolin, myricetin, ellagic acid and quercetin (John and Shahidi, 2010). Seventy percent aqueous acetone was used for extraction, which was the solvent mixture with the highest yield for total phenolics for both, kernel and brown skin, defatted or whole, when compared to methanol and ethanol (John and Shahidi, 2010). In another study, a higher yield was obtained using $40 \%$ aqueous ethanol, when compared to acetone and water combinations under optimized conditions for obtaining antioxidant extracts of the whole defatted nuts. Gallic acid, protocatechuic acid, 2,4-dihydroxybenzoic acid, $p$-hydroxybenzoic acid, $p$-coumaric acid, sinapic acid and catechin were identified in the ethanol/water extracts by RP-HPLC-DAD (Gomes and Torres, 2016). Phenolic compounds have been demonstrated to render protective effects against coronary heart disease such as by reducing platelet activity and inhibiting LDL oxidation (Lutz et al., 2019). To the best of our knowledge, there are no studies concerning stability of these phenolics during storage of Brazil nuts. Nevertheless, for comparison, no significant changes during 2 years of storage were observed for the content of phenolics in hazelnuts (Ghirardello et al., 2016). Aqueous extracts of bark biomass residues of the Brazil nut tree may be a relatively inexpensive source of antioxidants, with high amounts of ellagic acid derivatives present $(5.0 \mathrm{~g} / \mathrm{kg}$ for the outer bark and $44 \mathrm{~g} / \mathrm{kg}$ for the inner bark) (Silva et al., 2019). The major derivatives identified by RP-HPLC-DAD-MS/MS and NMR are eschweilenol C, ellagic acid and valoneic acid dilactone (Silva et al., 2019). The hard shell of the Brazil nut fruit should also be investigated as a source of antioxidants.

In summary, Brazil nut is a relevant source of antioxidant compounds, which are related to health benefits. These antioxidant compounds include Se, tocopherols, phenolic acids, and various flavonoid-derivatives. More investigations are needed to shed light on the effect of processing and storage on some of the bioactives in Brazil nuts and in their co-products. Less utilized parts of the Bertholletia excelsa tree may also be sources of antioxidants, which can be extracted in a relatively simple way and in abundant amounts. Brazil nuts have very high amounts of Se and could be more widely consumed, especially in regions of China and Scandinavia, which have a soil depleted in Se and where Se deficiency is a common problem among their populations. Se level in Brazil nuts vary from one seed to another and is strongly dependent on the origin. Hence, in order to assure safe consumption of Brazil nuts, recommendations of adding Se levels information based on the origin of the seeds in retail labelling should be made. Such labelling could also improve the image of Brazil nuts as a functional food worldwide.

\section{References}

Abe, L.T., Lajolo, F.M., and Genovese, M.I. (2010). Comparison of phenol content and antioxidant capacity of nuts. Ciência e Tecnologia de Alimentos. 30: 254-259.

Cardoso, B.R., Duarte, G.B.S., Reis, B.Z., and Cozzolino, S.M.F. (2017). Food Res. Int. 100: 9-18.

Chunhieng, T., Petritis, K., Elfakir, C., Brochier, J., Goli, T., and Montet, D. (2004). Study of selenium distribution in the protein fractions of the Brazil nut, Bertholletia excelsa. J. Agric. Food Chem. 52: 4318-4322.

Duarte, G.B.S., Reis, B.Z., Rogero, M.M., Vargas-Mendez, E., Barbosa Jr, F., Cercato, C., and Cozzolino, S.M.F. (2019). Consumption of Brazil nuts with high selenium levels increased inflammation biomarkers in obese women: A randomized controlled trial. Nutrition. 63-64: 162-168.

Food and Drug Administration-FDA. (2003). Qualified Health Claims: Letter of Enforcement Discretion-Nuts and Coronary Heart Disease, Docket $\mathrm{n}^{\circ}$ 02P-0505. FDA, Washington, DC.

Ghirardello, D., Bertolino, M., Belviso, S., Dal Bello, B., Giordano, M., Rolle, L., Gerbi, V., Antonucci, M., Spigolon, N., and Zeppa, G. (2016). Phenolic composition, antioxidant capacity and hexanal content of hazelnuts (Corylus avellana L.) as affected by different storage conditions. Postharvest Biol. Technol. 112: 95-104.

Gomes, S., and Torres, A.G. (2016). Optimized extraction of polyphenolic antioxidant compounds from Brazil nut (Bertholletia excelsa) cake and evaluation of the polyphenol profile by HPLC. J. Sci. Food Agric. 96: 2805-2814.

Gutierrez, E.M.R., Regitano-d'Arce, M.A.B., and Rauen-Miguel, A.M.O. (1997). Estabilidade oxidativa do óleo bruto da castanha-do-pará (Bertholletia excelsa). Ciência e Tecnologia de Alimentos. 17: 22-27.

Halliwell, B. (1990). How to characterize a biological antioxidant. Free Radical Res. Commun. 9: 1-32.

Jiang, Q. (2019). Natural forms of vitamin E and metabolites - regulation of cancer cell death and underlying mechanisms. IUBMB Life. 71: 495-506.

John, J.A., and Shahidi, F. (2010). Phenolic compounds and antioxidant activity of Brazil nut (Bertholletia excelsa). J. Functional Foods 2: 196-210. 
Kamal-Eldin, A., and Appelqvist, L.Å. (1996). The chemistry and antioxidant properties of tocopherols and tocotrienols. Lipids. 31: 671-701.

Kannamkumarath, S.S., Wrobel, K., Vonderheide, A., and Caruso, J.A. (2002). HPLC-ICP-MS determination of selenium distribution and speciation in different types of nut. Anal. Bioanal. Chem. 373: 454-460.

Kornsteiner, M., Wagner, K.H., and Elmadfa, I. (2006). Tocopherols and total phenolics in 10 different nut types. Food Chem. 98: 381-387.

Lemire, M., Philibert, A., Fillion, M., Passos, C.J.S., Guimarães, J.R.D., Barbosa, F., and Mergler, D. (2012). No evidence of selenosis from a selenium-rich diet in the Brazilian Amazon. Environment international. 40: 128-136.

Li, G.X., Lee, M.J., Liu, A.B., Yang, Z., Lin, Y., Shih, W.J., and Yang, C.S. (2011). $\delta$-Tocopherol is more active than $\alpha$ - or $\gamma$-tocopherol in inhibiting lung tumorigenesis in vivo. Cancer Prev. Res. 4: 404-413.

Lutz, M., Fuentes, E., Ávila, F., Alarcón, M., and Palomo, I. (2019). Roles of Phenolic Compounds in the Reduction of Risk Factors of Cardiovascular Diseases. Molecules. 24: 366.

Martens, I.B.G., Cardoso, B.R., Hare, D.J., Niedzwiecki, M.M., Lajolo, F.M. Martens, A.M., and Cozzolino, S.M.F. (2015). Selenium status in preschool children receiving a Brazil nut-enriched diet. Nutrition. 31: 1339-1343.

Miraliakbari, H., and Shahidi, F. (2008a). Oxidative stability of tree nut oils. J. Agric. Food Chem. 56: 4751-4759.

Miraliakbari, H., and Shahidi, F. (2008b). Lipid class compositions, tocopherols and sterols of tree nut oils extracted with different solvents. J. Food Lipids. 15: 81-96.

Miraliakbari, H., and Shahidi, F. (2008c). Antioxidant activity of minor components of tree nut oils. Food Chem. 111: 421-427.

Mortensen, A., and Skibsted, L.H. (1997). Relative stability of carotenoid radical cations and homologue tocopheroxyl radicals. A real time kinetic study of antioxidant hierarchy. FEBS Letters. 417: 261-266.

Regitano-d'Arce, M.A.B. (1998). Castanha do Pará: óleo e subprodutos sob a ótica da lipidologia. University of São Paulo, Piracicaba, p. 64

Sartori, A.G.O., Alencar, S.M., Bastos, D.H.M., Regitano-d'Arce, M.A.B., and Skibsted, L.H. (2018b). Effect of water activity on lipid oxidation and nonenzymatic browning in Brazil nut flour. Eur. Food Res. Technol. 244: 1657-1663.

Sartori, A.G.O., Machado, M.C., Bastos, D.H.M., Alencar, S.M., and Regitano-d'Arce, M.A.B. (2020). Water-extracted Brazil nut co-products: nutritional value and estimation of nutrient losses during processing J. Food Measurement Charac. doi:10.1007/s11694-020-00439-8.
Sartori, A.G.O., Sampaio, G.R., Bastos, D.H.M., Regitano d'Arce, M.A.B. and Skibsted, L.H. (2018a). Volatiles and tendency of radical formation of cold-pressed Brazil nut oil during ambient storage. J. Am. Oil Chem. Soc. 95: 721-730.

Sartori, A.G.O., Sampaio, G.R., Bastos, D.H.M., Spoto, M.H.F., Skibsted, L.H., and Regitano-d'Arce, M.A.B. (2018c). Tendency of lipid radical formation and volatiles in lose or vacuum-packed Brazil nuts stored at room temperature or under refrigeration. Grasas y Aceites 69: e283.

Silva, E.C. Jr, Wadt, L.H.O., Silva, K.E., Lima, R.M.B., Batista, K.D., Guedes, M.C., Carvalho, G.S., Carvalho, T.S., Reis, A.R., Lopes, G., and Guilherme, L.R.G. (2017). Natural variation of selenium in Brazil nuts and soils from the Amazon region. Chemosphere 188: 650-658.

Silva, F.M.A., Hanna, A.C.S., Souza, A.A., Silva-Filho, F.A., Canhoto, O.M.F., Magalhães, A., Benevides, P.J.C., Azevedo, M.B.M., Siani, A.C., Pohlit, A.M., Souza, A.D.L., and Koolen, H.H.F. (2019). Integrative Analysis Based on HPLC-DAD-MS/MS and NMR of Bertholletia excelsa Bark Biomass Residues: Determination of Ellagic Acid Derivatives. J. Braz. Chem. Soc. 30: 830-836.

Tsai, J.H., Hiserodt, R.D., Ho, C.T., Hartman, T.G., and Rosen, R.T. (1998). Determination of volatile organic selenium compounds from the Maillard Reaction in a selenomethionine-glucose model system. J Agric. Food Chem. 46: 2541-2545.

United States Department of Agriculture-USDA. (2019). National nutrient database for standard reference. https://fdc.nal.usda.gov/fdc-app. html\#/?query=ndbNumber:12078. Accessed 22 Jan 2020.

Universidade Estadual de Campinas -Unicamp. (2006). Tabela Brasileira de Composição de Alimentos. Unicamp, Campinas.

Venkatachalam, M., and Sathe, S.K. (2006). Chemical composition of selected edible nut seeds. J. Agric. Food Chem. 54: 4705-4714.

Vieira, T.M., and Regitano-d'Arce, M.A. (1999). Antioxidant concentration effect on stability of Brazil nut (Bertholletia excelsa) crude oil. Archivos Latinoamericanos de Nutricion 49: 271-274.

Wu, X., Beecher, G.R., Holden, J.M., Haytowitz, D.B., Gebhardt, S.E., and Prior, R.L. (2004). Lipophilic and hydrophilic antioxidant capacities of common foods in the United States. J. Agric. Food Chem. 52: 40264037.

Zajdenwerg, C., Branco, G.F., Alamed, J., Decker, E.A., and Castro, I.A. (2011). Correlation between sensory and chemical markers in the evaluation of Brazil nut oxidative shelf life. Eur. Food Res. Technol. 233: 109-116. 